Journal of Business Administration Vol 3, No 1, Maret 2019, hlm. 29-39. e-ISSN:2548-9909

\title{
ANALISIS RESIKO KESELAMATAN DAN KESEHATAN KERJA (K3) DENGAN MENGGUNAKAN METODE HAZARD AND OPERABILITY STUDY (HAZOP) PADA BAGIAN HYDROTEST MANUAL DI PT. CLADTEK BI METAL MANUFACTURING
}

\author{
Suci Oktavia Dwi Ningsih', Shinta Wahyu Hati \\ Jurusan Manajemen Bisnis, Politeknik Negeri Batam, Batam, 29461, \\ e-mail: sucioktavia1@gmail.com, shinta@polibatam.ac.id
}

\begin{abstract}
Abstrak
Penelitian ini mengenai Analisis Resiko Keselamatan dan Kesehatan Kerja (K3) dengan Metode Hazard and Operability Study (HAZOP) penelitian bertujuan untuk mengidentifikasi potensi bahaya menggunakan Job Safety Analysis (JSA), penilaian risiko, pengendalian risiko, dan pemantauan dan evaluasi. Penelitian ini dilakukan di PT. Cladtek Bi-Metal Manufacturing, data dalam penelitian ini diperoleh melalui pengamatan secara langsung, dokumentasi, serta wawancara dengan tujuh orang informan yaitu: HSE Manager, Staff HSE, Safety Officer dan empat orang pekerja Hydrotest Manual. Metode penelitian ini menggunakan metode deskriptif kualitatif. Langkah dalam melakukan analisis data yaitu mengetahui urutan proses produksi, mengidentifikasi potensi bahaya, mengetahui analisis potensi bahaya dengan Job Safety Analysis (JSA), penilaian resiko, pengendalian resiko, pemantauan dan evaluasi, analisis dan pembahasan, dan penarikan kesimpulan.Hasil penelitian menunjukkan PT. Cladtek pada bagian Hydrotest Manual terdapat potensi bahaya dengan rata-rata bahaya resiko sedang, JSA dapat menurunkan resiko kecelakaan kerja, potensi kecelakaan kerja jarang terjadi, dapat mengendalikan resiko dimasa yang akan datang, pemantauan dan evaluasi baik.
\end{abstract}

Kata kunci: HAZOP, Hydrotest Manual, K3, Kecelakaan 


\section{PENDAHULUAN}

Tahun 2016 adalah tahun di mana kebijakan MEA (Masyarakat Ekonomi Asean) atau dalam istilah asing MEA disebut sebagai ASEAN Economics Community, mulai diterapkan oleh pemerintah Negara-negara ASEAN, termasuk Indonesia. Artinya, tenaga kerja asing akan banyak di Negara ini. Begitu pula sebaliknya, pekerja Indonesia akan tersebar di beberapa Negara ASEAN. MEA diterapkan agar daya asing ASEAN meningkat serta bisa menyaingi Tiongkok dan India untuk menarik investasi asing. Penanaman modal asing di wilayah ini sangat dibutuhkan untuk meningkatkan lapangan pekerjaan dan menyejahterahkan penduduk Negara ASEAN.

Masyarakat Ekonomi ASEAN tidak hanya membuka arus perdagangan barang atau jasa, tetapi juga para tenaga kerja Profesional yang ahli di bidang-bidangnya masing-masing, MEA secara langsung akan mempengaruhi kualitas tenaga ahli di Indonesia (www.suaraBMR.com, 2016).

Dengan adanya MEA tersebut tentu akan membuat tenaga kerja lokal menjadi khawatir mengenai lapangan pekerjaan dan mereka yang memiliki keterbatasan pengetahuan dan bahasa untuk persaingan dalam mendapatkan pekerjaan, hal ini akan membuat tenaga kerja lokal harus mampu bersaing secara sehat untuk mendapatkan pekerjaan, namun tidak jarang ada yang bersaing dengan tidak sehat maksudnya adalah dengan menghalalkan segala cara agar mendapatkan pekerjaan. Dengan semakin ketatnya persaingan untuk mendapatkan sebuah pekerjaan, sering kali melupakan yang namanya keahlian dan pengetahuan yang merupakan hal penting untuk melakukan suatu pekerjaan terutama pekerjaan yang memiliki resiko tinggi kecelakaan.

Suara pembaharuan 2014 dalam Hati (2014) menyatakan bahwa kasus kecelakaan kerja yang terjadi di Indonesia meningkat setiap tahunnya yaitu sebanyak 93.000

kasus

(www.bpjsketenagakerjaan.go.id).
Menurut data Kementerian Tenaga Kerja dan Transmigrasi menyebutkan, di Indonesia sampai dengan tahun 2013 tercatat kecelakaan kerja yang mengakibatkan meninggal dunia sebanyak tidak kurang dari enam pekerja setiap harinya. Angka tersebut tergolong tinggi dibandingkan Eropa, di Negara Eropa per hari meninggal sebanyak dua orang yang disebabkan oleh kecelakaan kerja. Menurut data Internasional Labor Organization (ILO), di Indonesia rata-rata per tahun terdapat kecelakaan kerja sebanyak 99.000 kasus, mengakibatkan $70 \%$ kematian dan cacat seumur hidup.

Penyebab dari kecelakaan kerja bisa datang kapan, di mana dan kepada siapa saja, terhadap yang beresiko mengalami kecelakaan kerja yang ditimbulkan karena faktor kesengajaan atau tidak. Dari sebuah Modul tentang Keselamatan dan Kesehatan Kerja di Tempat Kerja (2009) bahwa, potensi bahaya keselamatan dan kesehatan kerja dapat di mana dan kepada siapa saja. Resiko bisa berakibat fatal atau hanya kecelakaan kecil, tergantung pada tingkat peluang bahaya yang ada.

Penyebab dari gangguan kesehatan dan keselamatan kerja dikarenakan suatu bahaya kesehatan akan muncul apabila seseorang kontak dengan sesuatu yang dapat menyebabkan gangguan atau kerusakan bagi tubuh ketika terjadi pekerjaan yang berlebih. Bahaya kesehatan dapat menyebabkan penyakit yang disebabkan oleh pekerjaan suatu sumber bahaya di tempat kerja. Potensi bahaya kesehatan biasanya berasal dari lingkungan kerja diantaranya faktor kimia, faktor fisik, faktor biologi, faktor ergonomis, dan faktor psikologi. Maka dari itu Keselamatan dan Kesehatan Kerja sangat penting untuk kepentingan diri sendiri dan lingkungan tempat kita bekerja.

Menurut Lestari, Trisyulianti (2009) Keselamatan dan Kesehatan Kerja (K3) adalah suatu program yang dibuat pekerja maupun pengusaha sebagai upaya mencegah timbulnya kecelakaan dan penyakit akibat kerja, dengan cara 
mengenali hal-hal yang berpotensi menimbulkan kecelakaan dan penyakit akibat kerja serta tindakan antisipatif apabila terjadi kecelakaan dan penyakit akibat kerja. Tujuan dari dibuatnya program K3 adalah untuk mengurangi biaya perusahaan apabila timbul kecelakaan dan penyakit akibat kerja.

Untuk meminimalisir angka kecelakaan kerja atau menghilangkan angka kecelakan kerja perlu dilakukan sebuah langkah antisipasi baik dari pihak pekerja maupun pihak manajemen perusahaan. Kesadaran karyawan terhadap Keselamatan dan Kesehatan Kerja ditunjukkan dengan Sikap Profesional yang dibutuhkan oleh perusahaan, sesuai dengan penelitian Hati (2014) Sikap Profesioanal karyawan ditunjukkan dengan menjalankan prosedur K3 dan kesadaran yang ditanamkan sejak pembelajaran Mahasiswa di Laboratorium.

Kesadaran terhadap K3

meminimalkan resiko kecelakaan di perusahaan. Di antaranya menurut Hati \& Irawati (2016) bahwa melakukan pekerjaan sesuai dengan standard dan prosedur kerja adalah bagian dari keterampilan kerja, sikap melakukan pekerjaan sesuai prosedur adalah bagian dari sikap professional dalam bekerja. Sesuai dengan penelitian Hati \& Wahyuni (2016) ada kesadaran karyawan dalam mematuhi prosedur untuk meminimalkan resiko kecelakaan di tempat kerja. Maka diperlukan suatu menajemen risiko kegiatannya meliputi identifikasi bahaya, analisis potensi bahaya, penilaian risiko, pengendalian risiko, serta pemantauan dan evaluasi.

Menurut Restuputri \& Sari (2015), bahwa untuk mengurangi atau menghilangkan bahaya yang dapat menyebabkan kecelakaan di tempat kerja maka diperlukan suatu manajemen risiko kegiatannya meliputi identifikasi bahaya, analisis potensi bahaya, penilaian risiko, pengendalian risiko, serta pemantauan dan evaluasi. Dalam proses identifikasi dan melakukan analisis potensi bahaya dapat menggunakan metode Hazard and Operability study (HAZOP).

HAZOP adalah studi keselamatan yang sistematis, berdasarkan pendekatan sistemik ke arah penilaian keselamatan dan proses pengoperasian peralatan yang kompleks, atau proses produksi (Kotek dalam Restuputri \& Sari, 2015). Tujuannya untuk mengidentifikasi kemungkinan bahaya yang muncul dalam fasilitas pengelolaan di perusahaan menghilangkan sumber utama kecelakaan, seperti rilis beracun, ledakan dan kebakaran (Dunjo dalam Restuputri \& Sari, 2015).

Berdasarkan hasil penelitian yang dilakukan oleh Restuputri \& Sari (2015) bahwa HAZOP itu sendiri secara sistematis bekerja dengan mencari berbagai faktor penyebab (cause) yang memungkinkan timbulnya kecelakaan kerja dan menentukan konsekuensi yang merugikan sebagai akibat terjadinya penyimpangan serta memberikan rekomendasi atau tindakan yang dapat dilakukan untuk mengurangi dampak dari potensi risiko yang telah diidentifikasi.

\section{TUJUAN PENELITIAN}

Adapun tujuan dari penelitian ini adalah:

1. Untuk mengetahui dan menganalisis identifikasi bahaya terhadap Keselamatan dan Kesehatan Kerja dengan metode Hazop.

2. Untuk mengetahui analisis potensi bahaya terhadap Keselamatan dan Kesehatan Kerja dengan metode Hazop.

3. Untuk mengetahui penilaian risiko terhadap Keselamatan dan Kesehatan Kerja dengan metode Hazop.

4. Untuk mengetahui pengendalian risiko terhadap Keselamatan dan Kesehatan Kerja dengan metode Hazop.

5. Untuk mengetahui pemantuan dan evaluasi bahaya terhadap Keselamatan dan Kesehatan Kerja dengan metode Hazop

MANFAAT PENELITIAN

Adapun manfaat dari penelitian ini adalah: 
1. Manfaat praktis yaitu penulis mendapatkan ilmu secara langsung maupun tidak langsung, penulis juga mendapatkan tambahan ilmu tentang Keselamatan dan Kesehatan Kerja (K3) dengan menggunakan metode HAZOP yang ada di perusahaan yang penulis teliti.

2. Manfaat teoritis yaitu dapat memahami dan mengimplementasikan

Keselamatan dan Kesehatan Kerja (K3) dengan metode HAZOP untuk memberikan rasa aman dan nyaman pada saat bekerja.

\section{KAJIAN PUSTAKA}

\section{Keselamatan dan Kesehatan Kerja (K3)}

Menurut Lestari, Trisyulianti (2009) adalah suatu program yang dibuat pekerja maupun pengusaha sebagai upaya mencegah timbulnya kecelakaan dan penyakit akibat kerja, dengan cara mengenali hal-hal yang berpotensi menimbulkan kecelakaan dan penyakit akibat kerja serta tindakan antisipatif apabila terjadi kecelakaan dan penyakit akibat kerja. Lebih lanjut Lestari, Trsyulianti (2009) menyatakan bahwa tujuan dari dibuatnya program K3 adalah untuk mengurangi biaya perusahaan apabila timbul kecelakaan dan penyakit akibat kerja.

Menurut Hamali (2016) keselamtan dan kesehatan kerja telah menjadi perhatian di kalangan pemerintahan dan pelaku bisnis sejak lama. Faktor keselamatan kerja menjadi penting karena sangat terkait dengan kinerja karyawan dan pada gilirannya terhadap kinerja perusahaan. Fasilitas keselamatan kerja yang tersedia di perusahaan akan membuat semakin sedikit kemungkinan terjadinya kecelakaan kerja.

\section{Hazard and Operability Study (HAZOP)}

Menurut Karthika (2013), A hazard and operability study (HAZOP) is a structured and systematic examination of a planned or existing process or operation in order to identify and evaluate problems that may represent risk to personnel or equipment, or prevent efficient operation. The HAZOP technique was initially developed to analyze chemical process systems, but has later been extended to other types of systems and also to complex operations such as boiler operation and to record the deviation and consequence. A HAZOP is a qualitative technique based on guidewords and is carried out by a multidisciplinary team (HAZOP team) during a set of meetings.

Dimaksudkan adalah "bahaya dan pengoperasian studi (HAZOP) adalah pemeriksaan terstruktur dan sistematis yang direncanakan atau proses atau operasi yang ada untuk mengidentifikasi dan mengevaluasi masalah yang mungkin mewakili resiko untuk personil atau peralatan, atau mencegah efisien operasi. Teknik HAZOP awalnya dikembangkan untuk menganalisis sistem proses kimia, tetapi kemudian telah diperluas dengan jenis lain dari sistem dan juga untuk operasi yang kompleks seperti operasi boiler dan untuk merekam deviasi dan konsekuensi. HAZOP adalah teknik kualitatif berdasarkan guiedewords dan dilakukan oleh multi-disiplin (Tim HAZOP) selama serangkaian pertemuan".

Menurut Restuputri \& Sari (2015), menyatakan bahwa untuk mengurangi atau menghilangkan bahaya yang dapat menyebabkan kecelakaan di tempat kerja maka diperlukan suatu manajemen risiko kegiatannya meliputi identifikasi bahaya, analisis potensi bahaya, penilaian risiko, pengendalian risiko, serta pemantauan dan evaluasi. Dalam proses identifikasi dan melakukan analisis potensi bahaya dapat menggunakan metode Hazard and Operability study (HAZOP).

Berdasarkan hasil penelitian yang dilakukan oleh McKay (2011), bahwa teknik analisis HAZOP didasarkan pada prinsip dari beberapa ahli dengan latar belakang yang berbeda dapat berinteraksi secara kreatif, yang secara sistematis dan mengidentifikasi lebih banyak masalah 
ketika bekerja bersama-bersama dari pada ketika bekerja secara terpisah dan menggabungkan hasil mereka. Meskipun teknik HAZOP Study pada awalnya dikembangkan untuk evaluasi desain baru atau teknologi, itu berlaku untuk proses hampir semua fase seumur hidup.

\section{METODE}

Jenis penelitian yang digunakan adalah jenis penelitian menggunakan penelitian deskriptif kualitatif. Penelitian ini menggambarkan sejumlah data yang kemudian dianalisis dan dibandingkan berdasarkan kenyataan yang sedang berlangsung. Penelitian ini memusatkan perhatian keselamatan dan kesehatan kerja dengan menggunakan metode Hazard and Operability Study (HAZOP).

Langkah-langkah yang dilakukan pada tahapan pengumpulan dan pengolahan data adalah sebagai berikut:

1. Mengetahui urutan proses yang ada pada proses produksi.

2. Mengidentifikasi adanya potensi dengan cara observasi lapangan secara langsung.

3. Mengetahui analisis potensi bahaya dengan menggunakan Job Safety Analysis (JSA).

4. Melakukan penilaian dari potensi bahaya yang telah diidentifikasi menggunakan JSA dengan memperhitungkan Likelihood dan consequences, kemudian menggunakan risk matrix untuk mengetahui prioritas potensi bahaya yang harus diberi prioritas untuk diperbaiki.

5. Pengendalian resiko terhadap keselamatan dan kesehatan kerja

6. Pemantauan dan evaluasi bahaya terhadap keselamatan dan kesehatan kerja

7. Kesimpulan dan Saran, untuk menemukan jawaban dari semua permasalahan yang diangkat dalam penelitian ini. Berdasarkan dengan hasil pengambilan kesimpulan maka dapat diberikan saran ataupun beberapa masukan usulan perbaikan dalam upaya meningkatkan kinerja dan produktivitas perusahaan.

\section{HASIL DAN PEMBAHASAN}

\section{A. Proses Produksi}

Untuk mengidentifikasi bahaya apa saja yang terdapat pada proses produksi di PT. Cladtek Bi-Metal Manufacturing maka perlu diketahui alur dari proses produksi tersebut. Proses produksi Hydrotest Manual di PT. Cladtek adalah sebagai berikut:

1. Pipa masuk, yaitu pipa yang akan dilakukan pengecekan menggunakan hydrotest manual diletakkan pada bagian proses produksi Hydrotest Manual dengan menggunakan alat angkut dan alat angkat yaitu Forklift atau Overhead Crane.

2. Mempersiapkan komponen hydrotest dan aksesoris, yaitu mempersiapkan semua kebutuhan dan juga peralatan untuk keperluan pengecekan menggunakan hydrotest manual.

3. Menghubungkan pipa dengan aksesoris.

4. Memeriksa sambungan pipa yaitu memeriksa kembali apakah sambungan pipa dari aksesoris yang digunakan untuk menyambungkan pipa tersebut telah terpasang dengan baik, apakah baut yang telah dipasang sudah terkunci dengan benar atau belum. Hal tersebut untuk mencegah terjadinya kecelakaan kerja berupa kegagalan pengecekan yang menyebabkan baut pada sambungan pipa terhempas ke udara dan mengenai pekerja yang ada di sekitar area kerja, apabila sambungan pipa belum benar maka kembali lagi ke tahap sebelumnya yaitu menghubungkan pipa dengan aksesoris.

5. Memindahkan pipa ke bungker yaitu pipa di letakkan di dalam bungker dimana adalah tempat proses pengecekan hydrotest tersebut, dan juga untuk mencegah terjadinya kecelakaan kerja yang tidak 
diinginkan, apabila terjadinya kegagalan pengecekan.

6. Menghubungkan semua aksesoris, yaitu menyambungkan aksesoris pada satu material ke material lain atau dari pipa elbow disambungkan dengan flange menggunakan aksesoris.

7. Hydrotest awal, yaitu percobaan atau pengetesan awal apakah ada kebocoran pada sambungan pipa atau tidak.

8. Memulai proses hydrotest, yaitu proses pengecekan menggunakan tekanan angin yang tinggi untuk memeriksa apakah pipa tersebut terdapat kebocoran atau tidak.

9. Menaikkan tekanan, yaitu mengisi material dengan tekanan air yang di pompa kedalam semua pipa dengan ukuran yang telah ditentukan atau sesuai standart.

10. Hydrotest mencapai tekanan, yaitu material telah dilakukan pengecekan dengan tekanan yang diinginkan, jika tidak mencapai tekanan yang diinginkan maka kembali lagi ke tahap sebelumnya yaitu menaikkan tekanan.

11. Stop dan mengosongkan tekanan, yaitu menghentikan tekanan air karena proses pengecekan menggunakan proses hydrotest telah mencapai tekanan.

12. Melepaskan pipa dari aksesoris, yaitu melepaskan semua aksesoris yang digunakan untuk menyambungkan semua material.

13. Memindahkan komponen dari bungker, yaitu memindahkan pipa kembali keluar dari bungker karena proses pengecekan telah selesai dilakukan.

14. Melepaskan sambungan pipa, elbow, dan $\mathrm{T}$, yaitu memisahkan kembali material antara pipa, elbow dan $\mathrm{T}$.

15. House keeping, yaitu membersihkan tempat kerja dari baut yang mungkin berserakan dan juga sisa air dari proses pengecekan tersebut.

16. Menyimpan kembali aksesoris, yaitu merapikan kembali perlengkapan atau aksesoris yang tadi digunakan untuk melakukan pengecekan tersebut.

\section{B. Mengidentifikasi adanya potensi bahaya}

Sebelum mengidentifikasi adanya potensi bahaya, diperlukan Job Safety Analysis (JSA) yang dalam pelaksanaannya form JSA tersebut diisi oleh seorang Supervisor dan diperiksa kembali oleh seorang Safety Officer.

\section{Mengetahui analisis potensi bahaya}

Sebelum mengidentifikasi adanya potensi bahaya, diperlukan Job Safety Analysis (JSA) untuk menganalisis potensi bahaya, berikut adalah form JSA

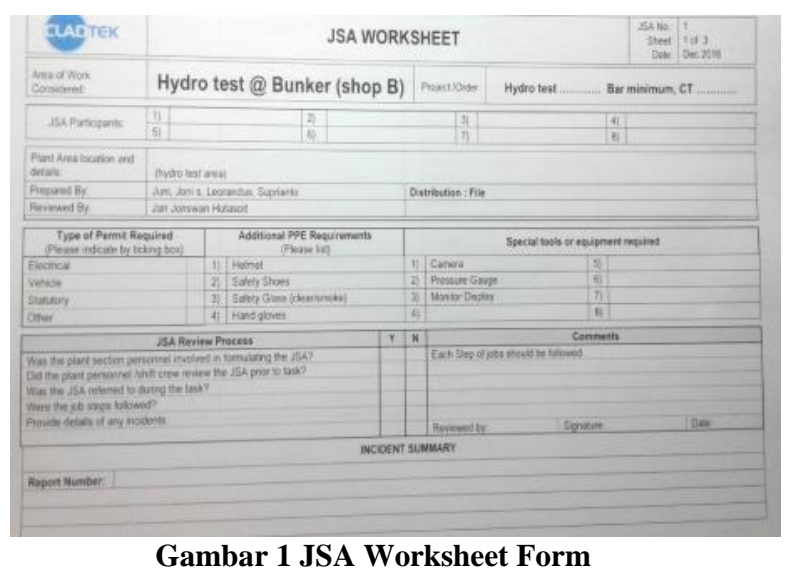

Setelah itu dilakukan observasi lapangan secara langsung dan wawancara terhadap informan untuk memperoleh temuan potensi bahaya. Tabel 1 menunjukkan hasil identifikasi hazard and risk.

Setelah itu, dilakukan penilaian resiko dengan memperhatikan kriteria tingkat keparahan sebagai berikut :

1. Likelihood (L) adalah kemungkinan terjadinya kecelakaan (tabel 2).

2. Consequences (C) adalah tingkat keparahan cidera dan kehilangan hari kerja (tabel 3). 
Suci \& Shinta, Analisis Risiko Keselamatan...

Tabel 1 Identifikasi hazard and risk

\begin{tabular}{|c|c|c|c|}
\hline No & Proses & Uraian Temuan Hazard & Resiko \\
\hline 1. & $\begin{array}{l}\text { Pipa Masuk/Datang } \\
\text { oleh Forklift/Crane }\end{array}$ & $\begin{array}{l}\text { a. Tertimpa Benda Jatuh } \\
\text { b. Terjepit oleh Benda } \\
\text { c. Kelelahan } \\
\text { d. Terbentur oleh benda yang diangkat }\end{array}$ & $\begin{array}{l}\text { a. Patah Tulang } \\
\text { b. Memar Kulit } \\
\text { c. Keseleo } \\
\text { d. Luka Robek }\end{array}$ \\
\hline 2. & $\begin{array}{l}\text { Mempersipkan } \\
\text { komponen Hydrotest } \\
\text { dan aksesorisnya }\end{array}$ & $\begin{array}{l}\text { a. Tertimpa Benda Jatuh } \\
\text { b. Terjepit oleh Benda } \\
\text { c. Salah posisi saat mengangkat }\end{array}$ & $\begin{array}{l}\text { a. Patah Tulang } \\
\text { b. Memar Kulit } \\
\text { c. Keseleo }\end{array}$ \\
\hline 3. & $\begin{array}{l}\text { Menghubungkan pipa } \\
\text { dengan aksesorisnya }\end{array}$ & $\begin{array}{l}\text { a. Jari terjepit pada saat mengencangkan baut } \\
\text { b. Berada di posisi yang tidak aman pada saat } \\
\text { menghubungkan pipa } \\
\text { c. Kejatuhan material }\end{array}$ & $\begin{array}{l}\text { a. Luka Robek } \\
\text { b. Patah Tulang } \\
\text { c. Terkilir }\end{array}$ \\
\hline 4. & $\begin{array}{l}\text { Memeriksa } \\
\text { sambungan pipa }\end{array}$ & $\begin{array}{l}\text { a. Tergelincir pada tingkat ketinggian yang } \\
\text { sama atau tanah datar } \\
\text { b. Kejatuhan material } \\
\text { c. Kelelahan }\end{array}$ & $\begin{array}{l}\text { a. Patah Tulang } \\
\text { b. Memar Kulit } \\
\text { c. Keseleo } \\
\text { d. Luka Robek }\end{array}$ \\
\hline 5. & $\begin{array}{l}\text { Memindahkan pipa } \\
\text { ke bungker }\end{array}$ & $\begin{array}{l}\text { a. Tertimpa Benda Jatuh } \\
\text { b. Terjepit oleh Benda } \\
\text { c. Kelelahan } \\
\text { d. Terbentur oleh benda yang diangkat }\end{array}$ & $\begin{array}{l}\text { a. Patah Tulang } \\
\text { b. Memar Kulit } \\
\text { c. Keseleo } \\
\text { d. Luka Robek }\end{array}$ \\
\hline 6. & $\begin{array}{l}\text { Menghubungkan } \\
\text { semua aksesoris } \\
\text { hydrotest manual ke } \\
\text { material }\end{array}$ & $\begin{array}{l}\text { a. Jari terjepit pada saat mengencangkan baut } \\
\text { b. Berada di posisi yang tidak aman pada saat } \\
\text { menghubungkan pipa } \\
\text { c. Kejatuhan material }\end{array}$ & $\begin{array}{l}\text { a. Luka Robek } \\
\text { b. Patah Tulang } \\
\text { c. Terkilir }\end{array}$ \\
\hline 7. & $\begin{array}{l}\text { Hydrotest awal untuk } \\
\text { menghilangkan udara } \\
\text { dan mencapai } \\
\text { stabilisasi }\end{array}$ & $\begin{array}{l}\text { a. Tertimpa Benda Jatuh } \\
\text { b. Terjepit oleh Benda } \\
\text { c. Kelelahan }\end{array}$ & $\begin{array}{l}\text { a. Patah Tulang } \\
\text { b. Memar Kulit } \\
\text { c. Keseleo } \\
\text { d. Luka Robek }\end{array}$ \\
\hline 8. & $\begin{array}{l}\text { Memulai Proses } \\
\text { Hydrotest }\end{array}$ & $\begin{array}{l}\text { a. Tertimpa Benda Jatuh } \\
\text { b. Terjepit oleh Benda } \\
\text { c. Kelelahan }\end{array}$ & $\begin{array}{l}\text { a. Patah Tulang } \\
\text { b. Memar Kulit } \\
\text { c. Keseleo } \\
\text { d. Luka Robek }\end{array}$ \\
\hline 9. & $\begin{array}{l}\text { Menaikkan tekanan } \\
\text { dengan pompa }\end{array}$ & $\begin{array}{l}\text { a. Tertimpa Benda Jatuh } \\
\text { b. Terjepit oleh Benda } \\
\text { c. Kelelahan }\end{array}$ & $\begin{array}{l}\text { a. Patah Tulang } \\
\text { b. Memar Kulit } \\
\text { c. Keseleo } \\
\text { d. Luka Robek }\end{array}$ \\
\hline 10. & $\begin{array}{l}\text { Hydrotest mencapai } \\
\text { tekanan }\end{array}$ & $\begin{array}{l}\text { a. Tertimpa Benda Jatuh } \\
\text { b. Terjepit oleh Benda } \\
\text { c. Kelelahan }\end{array}$ & $\begin{array}{l}\text { a. Patah Tulang } \\
\text { b. Memar Kulit } \\
\text { c. Keseleo } \\
\text { d. Luka Robek }\end{array}$ \\
\hline 11. & $\begin{array}{l}\text { Stop dan } \\
\text { mengosongkan } \\
\text { tekanan dalam pipa }\end{array}$ & $\begin{array}{l}\text { a. Tertimpa Benda Jatuh } \\
\text { b. Terjepit oleh Benda } \\
\text { c. Kelelahan }\end{array}$ & $\begin{array}{l}\text { a. Patah Tulang } \\
\text { b. Memar Kulit } \\
\text { c. Keseleo } \\
\text { d. Luka Robek }\end{array}$ \\
\hline 12. & $\begin{array}{l}\text { Melepaskan pipa dari } \\
\text { aksesoris }\end{array}$ & $\begin{array}{l}\text { a. Jari terjepit pada saat mengencangkan baut } \\
\text { b. Berada di posisi yang tidak aman pada saat } \\
\text { menghubungkan pipa } \\
\text { c. Kejatuhan material }\end{array}$ & $\begin{array}{l}\text { a. Luka Robek } \\
\text { b. Patah Tulang } \\
\text { c. Terkilir }\end{array}$ \\
\hline 13. & $\begin{array}{l}\text { Memindahkan } \\
\text { komponen dari } \\
\text { bungker oleh crane }\end{array}$ & $\begin{array}{l}\text { a. Tertimpa Benda Jatuh } \\
\text { b. Terjepit oleh Benda } \\
\text { c. Kelelahan } \\
\text { d. Terbentur oleh benda yang diangkat }\end{array}$ & $\begin{array}{l}\text { a. Patah Tulang } \\
\text { b. Memar Kulit } \\
\text { c. Keseleo } \\
\text { d. Luka Robek }\end{array}$ \\
\hline 14. & $\begin{array}{l}\text { Melepaskan } \\
\text { sambungan pipa, } \\
\text { elbow dan T }\end{array}$ & $\begin{array}{l}\text { a. Tertimpa Benda Jatuh } \\
\text { b. Terjepit oleh Benda } \\
\text { c. Kelelahan }\end{array}$ & $\begin{array}{l}\text { a. Patah Tulang } \\
\text { b. Memar Kulit } \\
\text { c. Keseleo } \\
\text { d. Luka Robek }\end{array}$ \\
\hline 15. & House Keeping & $\begin{array}{l}\text { a. Tergelincir pada tingkat ketinggian yang } \\
\text { sama atau tanah datar } \\
\text { b. Kelelahan }\end{array}$ & $\begin{array}{l}\text { a. Memar Kulit } \\
\text { b. Keseleo } \\
\text { c. Luka Robek }\end{array}$ \\
\hline
\end{tabular}




\begin{tabular}{|c|c|c|c|}
\hline \multicolumn{4}{|c|}{ c. Salah posisi pada saat mengangkat } \\
\hline $\begin{array}{l}\mathrm{M} \\
\mathrm{ak}\end{array}$ & $\begin{array}{l}\text { Menyimpan kembali } \\
\text { aksesoris hydrotest }\end{array}$ & \multicolumn{2}{|c|}{$\begin{array}{l}\text { a. Tergelincir pada tingkat ketinggian yang } \\
\text { sama atau tanah datar } \\
\text { b. Kelelahan } \\
\text { c. Salah posisi pada saat mengangkat } \\
\text { d. Tertimpa Benda Jatuh }\end{array}$} \\
\hline \multicolumn{4}{|c|}{ Tabel 2 Kemungkinan (Likelihood) } \\
\hline Tingkatan & Kriteria & Deskripsi Kualitatif & Semi Kualitatif \\
\hline 1 & Mungkin & $\begin{array}{l}\text { Kecelakaan secara teori dapat terjadi tapi } \\
\text { tidak mungkin. }\end{array}$ & $\begin{array}{l}\text { kurang dari } 1 \text { kali dalam } 5 \\
\text { tahun }\end{array}$ \\
\hline 2 & Rendah & Kecelakaan jarang terjadi. & terjadi 1 kali per 5 tahun \\
\hline 3 & Sedang & Kecelakaan terjadi sekali setahun. & $\begin{array}{l}1 \text { kali per } 3 \text { tahun sampai } 1 \text { kali } \\
\text { pertahun }\end{array}$ \\
\hline 4 & Tinggi & $\begin{array}{l}\text { Kecelakaan hampir terjadi bulanan atau } \\
\text { pertiga bulan. }\end{array}$ & $\begin{array}{l}\text { lebih dari } 1 \text { kali pertahun } \\
\text { hingga } 1 \text { kali per bulan }\end{array}$ \\
\hline 5 & Ekstrim & Kecelakaan sering terjadi dari hari ke bulan & lebih dari 1 kali per bulan \\
\hline \multicolumn{4}{|c|}{ Tabel 3 Keparahan (Consequences) } \\
\hline Tingkatan & Kriteria & Deskripsi Kualitatif & Semi Kualitatif \\
\hline 1 & Tidak ada & $\begin{array}{l}\text { Kejadian tidak menimbulkan kerugian atau } \\
\text { cidera pada manusia }\end{array}$ & $\begin{array}{l}\text { Tidak menyebabkan kehilangan } \\
\text { hari karja }\end{array}$ \\
\hline 2 & Rendah & $\begin{array}{l}\text { Menimbulkan cidera ringan, kerugian kecil } \\
\text { dan tidak menimbulkan dampak serius } \\
\text { terhadap kelangsungan bisnis. }\end{array}$ & $\begin{array}{l}\text { Masih dapat bekerja pada } \\
\text { hari/shift yang sama }\end{array}$ \\
\hline 3 & Serius & $\begin{array}{l}\text { Cedera berat dan dirawat dirumah sakit, } \\
\text { tidak menimbulkan cacat tetap, kerugian } \\
\text { finansial sedang }\end{array}$ & $\begin{array}{l}\text { Kehilangan hari kerja dibawah } \\
3 \text { hari }\end{array}$ \\
\hline 4 & Rentan & $\begin{array}{l}\text { Menimbulkan cidera parah dan cacat tetap } \\
\text { dan kerugian finansial besar serta } \\
\text { menimbulkan dampak serius terhadap } \\
\text { kelangsungan usaha }\end{array}$ & $\begin{array}{l}\text { Kehilangan hari kerja } 3 \text { hari } \\
\text { atau lebih }\end{array}$ \\
\hline 5 & Malapetaka & $\begin{array}{l}\text { Mengakibatkan korban meninggal dan } \\
\text { kerugian parah bahkan dapat menghentikan } \\
\text { kegiatan usaha selamanya. }\end{array}$ & $\begin{array}{l}\text { Kehilangan hari kerja } \\
\text { selamanya }\end{array}$ \\
\hline
\end{tabular}

Setelah menentukan nilai likelihood dan consequences dari masing-masing sumber potensi bahaya, maka langkah selanjutnya adalah mengalikan nilai likelihood dan consequences sehingga diperoleh tingkat bahaya (risk level) pada risk matrix yang mana nantinya akan digunakan dalam melakukan perangkingan terhadap sumber potensi bahaya yang akan dijadikan acuan sebagai rekomendasi perbaikan apa yang sesuai dengan permasalahan yang ada. Penilain risiko itu sendiri dilakukan dengan menggunakan risk matrix seperti pada gambar 2 .

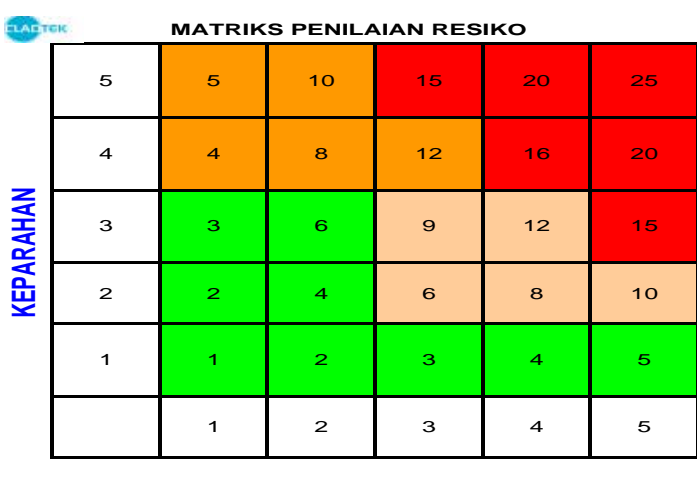

KEMUNGKINAN

Gambar 2 Risk Matrix

Dari risk matrix di atas kemudian dapat dihitung skor resiko dan prioritas untuk melakukan tindakan perbaikan. Untuk menghitung skor resiko adalah sebagai berikut:

Resiko $=$ Kemungkinan X Keparahan 
Suci \& Shinta, Analisis Risiko Keselamatan...

Tabel 4 Temuan Potensi Bahaya (Risk Level)

\begin{tabular}{|c|c|c|c|c|c|c|c|c|}
\hline NO & Proses & Temuan Hazard & Resiko & $\begin{array}{l}\text { Sumber } \\
\text { Hazard }\end{array}$ & $\mathbf{L}^{*}$ & $\mathbf{C}^{*}$ & $\mathbf{R}^{*}$ & Risk Level \\
\hline \multirow{3}{*}{1.} & \multirow{3}{*}{$\begin{array}{l}\text { Pipa Masuk/Datang } \\
\text { oleh Forklift/Crane }\end{array}$} & Tertimpa Benda Jatuh & Memar Kulit & Material & 3 & 3 & 9 & Sedang \\
\hline & & Terjepit oleh Benda & Luka Robek & Material & 3 & 3 & 9 & Sedang \\
\hline & & Kelelahan & Keseleo & Material & 3 & 3 & 9 & Sedang \\
\hline \multirow{3}{*}{2.} & \multirow{3}{*}{$\begin{array}{c}\text { Mempersipkan } \\
\text { komponen Hydrotest } \\
\text { dan aksesorisnya }\end{array}$} & Tertimpa Benda Jatuh & Memar Kulit & Material & 3 & 3 & 9 & Sedang \\
\hline & & Terjepit oleh Benda & Luka Robek & Material & 3 & 3 & 9 & Sedang \\
\hline & & $\begin{array}{l}\text { Salah posisi saat } \\
\text { mengangkat }\end{array}$ & Keseleo & Material & 3 & 3 & 9 & Sedang \\
\hline \multirow{3}{*}{3.} & \multirow{3}{*}{$\begin{array}{l}\text { Menghubungkan pipa } \\
\text { dengan aksesorisnya }\end{array}$} & $\begin{array}{l}\text { Jari terjepit pada saat } \\
\text { mengencangkan baut }\end{array}$ & Luka Robek & Material & 3 & 3 & 9 & Sedang \\
\hline & & $\begin{array}{l}\text { Berada di posisi yang } \\
\text { tidak aman pada saat } \\
\text { menghubungkan pipa }\end{array}$ & Luka Robek & Pipa & 3 & 3 & 9 & Sedang \\
\hline & & Kejatuhan Material & Patah Tulang & Pipa & 3 & 4 & 12 & Tinggi \\
\hline \multirow[t]{3}{*}{4.} & \multirow[t]{3}{*}{$\begin{array}{c}\text { Memeriksa } \\
\text { sambungan pipa }\end{array}$} & $\begin{array}{l}\text { Tergelincir pada } \\
\text { tingkat ketinggian } \\
\text { yang sama atau tanah } \\
\text { datar }\end{array}$ & Keseleo & Material & 3 & 3 & 9 & Sedang \\
\hline & & Kejatuhan material & Patah Tulang & Material & 3 & 4 & 12 & Tinggi \\
\hline & & Kelelahan & Memar Kulit & Material & 3 & 3 & 9 & Sedang \\
\hline \multirow{4}{*}{5.} & \multirow{4}{*}{$\begin{array}{c}\text { Memindahkan pipa ke } \\
\text { bungker }\end{array}$} & Tertimpa Benda Jatuh & Luka Robek & Material & 3 & 3 & 9 & Sedang \\
\hline & & Terjepit oleh Benda & Luka Robek & Material & 3 & 3 & 9 & Sedang \\
\hline & & Kelelahan & Memar Kulit & Material & 3 & 3 & 9 & Sedang \\
\hline & & $\begin{array}{l}\text { Terbentur oleh benda } \\
\text { yang diangkat }\end{array}$ & Memar Kulit & Material & 3 & 3 & 9 & Sedang \\
\hline \multirow{3}{*}{6.} & \multirow{3}{*}{$\begin{array}{c}\text { Menghubungkan } \\
\text { semua aksesoris } \\
\text { hydrotest manual ke } \\
\text { material }\end{array}$} & $\begin{array}{l}\text { Jari terjepit pada saat } \\
\text { mengencangkan baut }\end{array}$ & Luka Robek & Material & 3 & 3 & 9 & Sedang \\
\hline & & $\begin{array}{l}\text { Berada di posisi yang } \\
\text { tidak aman pada saat } \\
\text { menghubungkan pipa }\end{array}$ & Luka Robek & Pipa & 3 & 3 & 9 & Sedang \\
\hline & & Kejatuhan material & Patah Tulang & Material & 3 & 4 & 12 & Tinggi \\
\hline \multirow{3}{*}{7.} & \multirow{3}{*}{$\begin{array}{l}\text { Hydrotest awal untuk } \\
\text { menghilangkan udara } \\
\text { dan mencapai } \\
\text { stabilisasi }\end{array}$} & Tertimpa Benda Jatuh & Luka Robek & Material & 3 & 3 & 9 & Sedang \\
\hline & & Terjepit oleh Benda & Luka Robek & Material & 3 & 3 & 9 & Sedang \\
\hline & & Kelelahan & Memar Kulit & Material & 3 & 3 & 9 & Sedang \\
\hline \multirow{3}{*}{8.} & \multirow{3}{*}{$\begin{array}{c}\text { Memulai Proses } \\
\text { Hydrotest }\end{array}$} & Tertimpa Benda Jatuh & Luka Robek & Material & 3 & 3 & 9 & Sedang \\
\hline & & Terjepit oleh Benda & Luka Robek & Material & 3 & 3 & 9 & Sedang \\
\hline & & Kelelahan & Memar Kulit & Material & 3 & 3 & 9 & Sedang \\
\hline \multirow{3}{*}{9.} & \multirow{3}{*}{$\begin{array}{c}\text { Menaikkan tekanan } \\
\text { dengan pompa }\end{array}$} & Tertimpa Benda Jatuh & Luka Robek & Material & 3 & 3 & 9 & Sedang \\
\hline & & Terjepit oleh Benda & Luka Robek & Material & 3 & 3 & 9 & Sedang \\
\hline & & Kelelahan & Memar Kulit & Material & 3 & 3 & 9 & Sedang \\
\hline \multirow{3}{*}{10.} & \multirow{3}{*}{$\begin{array}{l}\text { Hydrotest mencapai } \\
\text { tekanan }\end{array}$} & Tertimpa Benda Jatuh & Luka Robek & Material & 3 & 3 & 9 & Sedang \\
\hline & & Terjepit oleh Benda & Luka Robek & Material & 3 & 3 & 9 & Sedang \\
\hline & & Kelelahan & Memar Kulit & Material & 3 & 3 & 9 & Sedang \\
\hline \multirow{3}{*}{11.} & \multirow{3}{*}{$\begin{array}{c}\text { Stop dan } \\
\text { mengosongkan } \\
\text { tekanan dalam pipa }\end{array}$} & Tertimpa Benda Jatuh & Luka Robek & Material & 3 & 3 & 9 & Sedang \\
\hline & & Terjepit oleh Benda & Luka Robek & Material & 3 & 3 & 9 & Sedang \\
\hline & & Kelelahan & Memar Kulit & Material & 3 & 3 & 9 & Sedang \\
\hline & & $\begin{array}{l}\text { Jari terjepit pada saat } \\
\text { mengencangkan baut }\end{array}$ & Luka Robek & Material & 3 & 3 & 9 & Sedang \\
\hline 12. & $\begin{array}{c}\text { air } \\
\text { angin dan mengalirkan }\end{array}$ & $\begin{array}{l}\text { Berada di posisi yang } \\
\text { tidak aman pada saat } \\
\text { menghubungkan pipa }\end{array}$ & Luka Robek & Pipa & 3 & 3 & 9 & Sedang \\
\hline & & Kejatuhan material & Patah Tulang & Material & 3 & 4 & 12 & Tinggi \\
\hline & & Tertimpa Benda Jatuh & Cedera & Material & 3 & 3 & 9 & Sedang \\
\hline & Memindahkan & Terjepit oleh Benda & Luka Robek & Material & 3 & 3 & 9 & Sedang \\
\hline 13. & komponen dari & Kelelahan & Memar Kulit & Material & 3 & 3 & 9 & Sedang \\
\hline & bungker oleh crane & $\begin{array}{l}\text { Terbentur oleh benda } \\
\text { yang diangkat }\end{array}$ & Memar Kulit & Material & 3 & 3 & 9 & Sedang \\
\hline & Melepaskan & Tertimpa Benda Jatuh & Cedera & Material & 3 & 3 & 9 & Sedang \\
\hline 14. & sambungan pipa, & Terjepit oleh Benda & Luka Robek & Material & 3 & 3 & 9 & Sedang \\
\hline & elbow dan T & Kelelahan & Memar Kulit & Material & 3 & 3 & 9 & Sedang \\
\hline 15. & House Keeping & Tergelincir pada & Luka Robek & Material & 3 & 3 & 9 & Sedang \\
\hline
\end{tabular}


Journal of Business Administration Vol 3, No 1, Maret 2019, hlm. 29-39

\begin{tabular}{|c|c|c|c|c|c|c|c|c|}
\hline & & $\begin{array}{l}\text { tingkat ketinggian } \\
\text { yang sama atau tanah } \\
\text { datar }\end{array}$ & & & & & & \\
\hline & & Kelelahan & Memar Kulit & Material & 3 & 3 & 9 & Sedang \\
\hline & & $\begin{array}{l}\text { Salah posisi pada saat } \\
\text { mengangkat }\end{array}$ & Keseleo & Material & 3 & 3 & 9 & Sedang \\
\hline \multirow{4}{*}{16.} & \multirow{4}{*}{$\begin{array}{l}\text { Menyimpan kembali } \\
\text { aksesoris hydrotest }\end{array}$} & Kelelahan & Memar Kulit & Material & 3 & 3 & 9 & Sedang \\
\hline & & Tertimpa Benda Jatuh & Cedera & Material & 3 & 3 & 9 & Sedang \\
\hline & & $\begin{array}{l}\text { Tergelincir pada } \\
\text { tingkat ketinggian } \\
\text { yang sama atau tanah } \\
\text { datar }\end{array}$ & Luka Robek & Material & 3 & 3 & 9 & Sedang \\
\hline & & $\begin{array}{l}\text { Salah posisi pada saat } \\
\text { mengangkat }\end{array}$ & Keseleo & Material & 3 & 3 & 9 & Sedang \\
\hline
\end{tabular}

\section{SIMPULAN DAN SARAN Simpulan}

Setelah dilakukan identifikasi terdapat potensi bahaya namun dengan rata-rata potensi bahaya (risk level) resiko sedang dan kemungkinan memerlukan kendali resiko, analisis potensi bahaya ternyata dapat menurunkan resiko kecelakaan kerja, penilaian resiko yang dinilai kecelakaan kerja yang terjadi memiliki kemungkinan sedang, yang artinya kecelakaan jarang terjadi dalam kurung waktu 1 (satu) tahun hanya terdapat 1 (satu) kali kecelakaan dalam konsekuensi yang serius, pengendalian resiko yang dilakukan sudah dapat mengendalikan resiko di masa yang akan datang, pemantauan dan evaluasi selama ini sudah dilakukan dengan baik.

\section{Saran}

Pertama Dalam proses produksi pada bagian hydrotes manual lebih mengutamakan faktor keselamatan dan lebih memperhatikan penggunaan alat pelindung diri yang telah disediakan pihak perusahaan, agar terhindar dari kecelakaan kerja. Kedua proses menganalisis potensi bahaya yang dilakukan benar-benar dilakukan oleh seorang yang berkompeten dibidang tersebut, agar tidak terjadi kesalahan dalam menganalisis potensi bahaya dengan Job Safety Analysis (JSA). Ketiga pada proses penilaian resiko juga diharapkan dilakukan oleh seorang yang berkompeten untuk melakukan penilaian dan juga seorang yang memang sudah berpengalaman melakukan penilaian bahaya tersebut, agar dapat benar-benar memperhitungkan faktor penyebab kecelakaan kerja tersebut. Keempat pada proses pengendalian resiko seorang safety officer dapat dengan tegas untuk melakukan tindakan terhadap para pekerja yang tidak mematuhi faktor keselamatan kerja yang dapat mengakibatkan kecelakaan kerja. Kelima dalam proses pemantauan dan evaluasi diharapkan benar-benar di lakukan khususnya untuk pihak manajemen yang bertugas untuk memantau dan mengevaluasi hal tersebut, untuk meminimalisir kecelakaan kerja.

\section{DAFTAR PUSTAKA}

Hamali, A.Y. S.S.,M.M (2016). Pemahaman Manajemen Sumber Daya Manusia. Cetakan pertama. Penerbit: CAPS (Center for Academic Publishing Service), Yogyakarta. Halaman 162-181. ISBN : (10) 6029324-77-2.

Hati, S.W. (2014). “Analisis Keselamatan dan kesehatan Kerja (K3) pada Pembelajaran di Laboratorium Program Studi Teknik Mesin Politeknik Negeri Batam". Proceeding Seminar Ekonomi Nasioanl (SNE 2014) Pembangunan Manusia Melalui Pendidikan dalam Menghadapi ASEAN Economic Community 2015, UNESA, Surabaya, 03 Mei 2014.

Hati, S.W; Irawati, R. (2016). "Analisis Faktor-Faktor yang Mempengaruhi Produktivitas Tenaga Kerja Wanita Bagian Operator Produksi pada Industri Manufaktur di Kawasan 
Batamindo Batam". Proceeding $3^{\text {rd }}$ Applied Business and Engineering Conference 2015. Halaman 1-13.

Hati, S.W; Wahyuni S. (2016). "The Effect of The Application of Work Safety and Health to Awareness of SOP (Standard Operating Procedure) on Employee Bulk (Subcontractor) Contructrion in The Company XYZ Batam". Dipersentasikan pada seminar ICAMESS 2016, 30 April 2016.

Karthika, S. (2013). “Accident Prevention by Using Hazop Study and Work Permit System in Boiler". International Journal of Advanced Engineering Research and Studies. Vol. 2, No. 2, Halaman 125-129. eISSN: 2249-8974

Restuputri, D.P; Sari, Dyan R.P. (2015). "Analisis Kecelakaan Kerja dengan Menggunakan Metode Hazard and Operability Study (HAZOP)". Jurnal Ilmiah Teknik Industri. Vol. 14, No. 1, Juni 2015 Halaman, 24-35. ISSN 1412-6869.

Varun, K; Karthikeyan, A. (2014). “Job Safety Analysis and Hazop for Fasteners Industry". International Journal of Scientific Engineering and Technology Research, Vol. 3, No. 7, Tahun 2014, Halaman 1278-1281.

Yuniar; Caecillia S.W; Zen H.R (2013). "Strategi Potensi Bahaya Berdasarkan Metode Hazard and Operability (HAZOP) di PT. Agronesia”. Jurnal online Institut Teknologi Nasional. Vol. 1, No. 1, ISSN 2338-508 